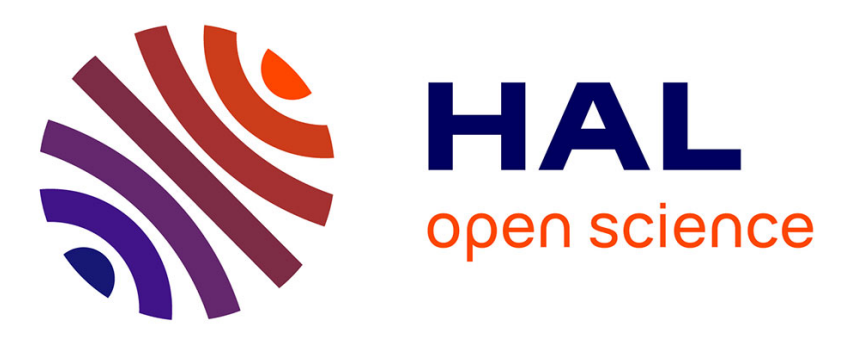

\title{
Shear strength measurements in a shock loaded commercial silastomer
}

\author{
J C F Millett, G Whiteman, S M Stirk, N K Bourne
}

\section{To cite this version:}

J C F Millett, G Whiteman, S M Stirk, N K Bourne. Shear strength measurements in a shock loaded commercial silastomer. Journal of Physics D: Applied Physics, 2011, 44 (18), pp.185403. 10.1088/0022-3727/44/18/185403 . hal-00614341

\section{HAL Id: hal-00614341 \\ https://hal.science/hal-00614341}

Submitted on 11 Aug 2011

HAL is a multi-disciplinary open access archive for the deposit and dissemination of scientific research documents, whether they are published or not. The documents may come from teaching and research institutions in France or abroad, or from public or private research centers.
L'archive ouverte pluridisciplinaire HAL, est destinée au dépôt et à la diffusion de documents scientifiques de niveau recherche, publiés ou non, émanant des établissements d'enseignement et de recherche français ou étrangers, des laboratoires publics ou privés. 
Reviewers and Editors Comments.

Reviewer 1 . The discussion of $\mathrm{c} 0$ and $\mathrm{S}$ after equation 5 has been amended to avoid confusion.

Editorial Board Comments. Figure 1 has been amended to include a side view of the target assembly which should aid interpretation. The caption has also been altered to reflect this 


\title{
Shear strength measurements in a shock loaded
}

\section{commercial silastomer}

\author{
J.C.F. Millett, G. Whiteman, S.M. Stirk and N.K. Bourne \\ AWE, Aldermaston, Reading, RG7 4PR. UK. \\ Jeremy.Millett@awe.co.uk
}

PACS. 62.50

The shock induced shear strength of a commercial silastomer, trade name Sylgard $184^{\mathrm{TM}}$ has been determined using laterally mounted manganin stress gauges. Shear strength has been observed to increase with increasing shock amplitude, in common with many other materials. Shear strength has also been observed to increase slightly behind the shock front as well. It is believed that a combination of polymer chain entanglement and cross linking between chains is responsible. Finally, a ramp on the leading edge of the lower amplitude stress traces has been observed. It has been suggested that this is due to shock induced collapse of free space between the polymer chains. Similar explanations have been used to explain the apparent non-linearity of the shock velocity with particle velocity at low shock amplitudes.

\section{Introduction}

Polymers are widely used in industry, and thus their exposure to situations were high loading rates, including shock loading are becoming increasingly prevalent. The manufacture of explosives for military and industrial applications is a good example, where materials such as polychlorotrifluoroethylene (PCTFE) [1] and hydroxyterminated polybutadiene (HTPB) [2, 3] are used as binder phases. Epoxy resins have also been used as the matrix phase in fibre based composites $[4,5]$, and as such their impact response is of interest to the 
aerospace industry where resistance to foreign object damage (FoD) and bird strike are a necessity. Interest in monolithic polymers such as neoprene (polychloroprene) [6] has attracted attention as it has been used in the protection of buildings to earthquake damage.

In the past few years, a systematic effort has been made to understand how molecular structure affects the shock response of various polymers. One of the major aims of this programme was to investigate the variation of shock induced shear strength $(\tau)$ both with impact or longitudinal stress $\left(\sigma_{\mathrm{x}}\right)$ and time behind the shock front itself. Such measurements are useful as they define the offset of the Hugoniot (longitudinal stress) from the hydrostatic pressure $(P)$ via the relation,

$$
\sigma_{x}=P+\frac{4}{3} \tau
$$

During shock loading, conditions of one-dimensional strain apply, and correspondingly, there must be a confining (or lateral) stress $\left(\sigma_{\mathrm{y}, \mathrm{z}}\right)$ orthogonal to the loading axis. Assuming that hydrostatic pressure is the average of all three components of stress, shear stress can be written in terms of these components of stress, thus,

$$
2 \tau=\sigma_{x}-\sigma_{y}
$$

A number of techniques have been employed to determine this value, including inclined impact [7], subtracting the calculated hydrostatic pressure from the measured Hugoniot stress [8] and the self consistent technique, where a simple load and release experiment is compared to one where the initial conditions are the same, but instead of releasing, a second shock is launched into the already shocked target [9]. However, from equation 2, it can be seen that shear strength can also be measured using suitably orientated manganin stress gauges. This methodology has been used by ourselves and others on a variety of materials 
including metals and alloys [10-12], ceramics and silicate glasses [13-15] and polymers [1618]. It can be seen that this is an invasive procedure, in that a manganin stress gauge must be introduced into a sectioned target assembly, and as such, it has been suggested that in doing so, the lateral stress recorded by the gauge is more a function of the layer of adhesive it sits in due to target assembly [19]. However, shock loading experiments below the Hugoniot Elastic Limit (HEL - the yield strength during one-dimensional strain) in ceramics and glasses using this technique show good agreement with the calculated elastic response, thus,

$$
2 \tau=\frac{1-2 v}{1-v} \sigma_{x}
$$

where $v$ is the Poisson's ratio. Further, comparison of a number of techniques, including lateral gauges in tungsten heavy alloys (WHAs), also show a high level of agreement, hence lending confidence to the technique [20].

In the case of polymers, lateral stress gauges have been used to examine the role of side group size (from the main carbon-carbon) backbone has been investigated through the study of polyethylene (PE - hydrogen), polypropylene (PP - methyl) and polystyrene (PS benzene) [18], showing that as the size of the side group increased, the level of strengthening increased. It was suggested that this increased the level of chain entanglement (tacticity) increased from PE to PS, thus increasing the necessary stress to achieve deformation. It was also suggested that both PP and PS showed evidence of increased crystallinity due to shock loading. Such a response has been observed in polyether etherketone (PEEK), where Millett et al. [21] showed a pronounced discolouration immediately behind the impact face during Taylor impact tests, and by Rae et al. [22], who in repeating these experiments, were able to quantify this response. In all four materials, a significant increase in shear strength was also observed behind the shock front $[17,18]$, again ascribed to a degree of tacticity between adjacent polymer chains. However, in the case of fluorinated polymers such as 
polytetrafluoroethylene (PTFE), PCTFE and polyvinylidene difluoride (PVDF), the situation is rather different $[23,24]$. Although in common with most polymers studied, shear strength was shown to increase with longitudinal stress, shear strength itself was observed to be near constant with time behind the shock front. As fluorine replaced hydrogen, moving from PE to PTFE, strength was observed to shift from an increase behind the shock front, due to chain tangling to a more constant response. It was suggested that this was due to a two fold process; the large fluorine atoms reducing the tacticity of the chains, combined with the large electro-negativity of fluorine increasing the van de Waals forces between chains which will also affect strengthening mechanisms. Interestingly, it was noted that PVDF had the greatest strength of all three materials in this study. It was proposed that the alternating pairs of hydrogen and fluorine atoms along the chain would enhance tacticity, whilst the presence of those alternating pairs would also modify local charge density along the chain, thus allowing the creation of additional attractive forces.

We now turn our attention to a cross linked silicone rubber, marketed under the trade name Sylgard $184^{\mathrm{TM}}$, and referred hence forth as Sylgard. Although it is used as a potting compound in systems subjected to high pressure loading, and that it has been used as a binder phase in polymer bonded explosives [25], it is perhaps surprising that very little information concerning its high strain-rate and shock response has reached the open literature. Winter et al. [26], in combination with previous data published in Marsh [25] showed that the material displayed a linear relationship between shock velocity $\left(U_{\mathrm{S}}\right)$ and particle velocity $\left(u_{\mathrm{p}}\right.$ - the velocity of material flow behind the shock front due to momentum transfer). Silicone based rubbers have also been proposed by Be'ery and Rosenberg [27] as a potential encapsulation for manganin stress gauges to increase their pressure capability. They suggested that this would be due to the reduction in shock induced conduction from pressure induced phase transformations in materials containing benzene rings such as epoxy based resins. Sander et al. [28], used an explosively generated shock of amplitude ca. 16 GPa and a maximum duration 30 ns to load Sylgard, monitoring its chemical response via 
mass spectrometer. Results showed that the polydimethylsiloxane polymer molecule decomposed into $\mathrm{n}$-mers of dimethylsiloxane with $\mathrm{n}$ in the range 1 to 7 . In addition, $\mathrm{n}$-mers with missing methyl groups were also seen. The authors interpreted this as evidence of limited shock induced decomposition, suggesting that the lowest energy products had insufficient time to form. Dattelbaum et al. [29], used diamond anvil techniques to compress Sylgard up to $10 \mathrm{GPa}$. They also used Raman spectroscopy, and were able to rule out pressure induced crystallization or phase transformations up to $6 \mathrm{GPa}$. Their results indicated close agreement between static and shock generated results. Hooper et al. [30], used molecular dynamics, based on simple quantum-chemistry based potentials to model a range of polymers, included Sylgard. Comparisons of predicted and experimentally determined compression, bulk modulus and shock response all showed good agreement.

In this paper, we use laterally mounted manganin stress gauges to measure the variation of shear strength in Sylgard, both with induced shock stress and time behind the shock front. We also re-examine the Hugoniot data generated by Winter and his colleagues [26] in light of past experience with other polymeric materials.

\section{Experimental}

All shots were performed using a $70 \mathrm{~mm}$ diameter, $3 \mathrm{~m}$ long single stage gas gun. Impact stresses in the range 0.52 to $2.03 \mathrm{GPa}$ were induced by impacting $6 \mathrm{~mm}$ flyer plates of either Dural (aluminium alloy 6082-T6) or copper, whose shock response is well documented [25]. As Sylgard is a castable, two part resin, targets were manufactured as follows. An accurately machined Dural ring, inner diameter $c a .65 \mathrm{~mm}$ by $10 \mathrm{~mm}$ deep was placed in the centre of a $2 \mathrm{~mm}$ thick driver plate of either Dural or copper, matched to the flyer. The driver plate was of diameter $120 \mathrm{~mm}$, to allow the target assembly to be located accurately at the end of the gun. An accurately machined square bar of polymethylmethacrylate (PMMA) $\left(10 \times 10 \times 80 \mathrm{~mm}^{3}\right)$ was used to support a manganin stress gauge (MicroMeasurements type J2M-SS-580SF-025) within the ring, such that the active 
element was $c a .4 \mathrm{~mm}$ from the surface of the driver plate. The active width of the gauge itself is $c a .240 \mu \mathrm{m}$, which gives a high degree of temporal resolution, allowing features on the rising part of the shock pulse to be identified. For example, using the elastic wave speed

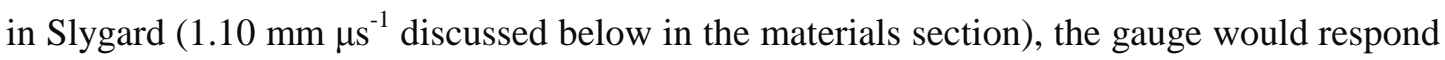
in $c a .220 \mathrm{~ns}$. Gauge calibrations were according to the work of Rosenberg et al. [31], which accounts for the shape effects of lateral gauge results at low stresses. A schematic representation of the target assembly and gauge placement is shown below in figure 1 .
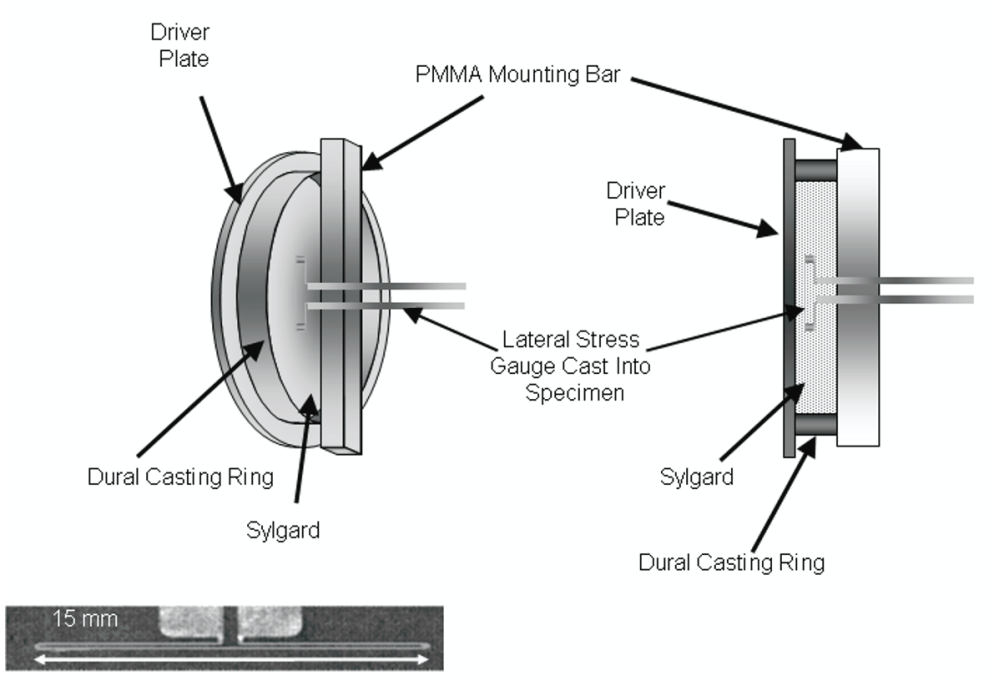

Active Width $=240 \mathrm{~km}$

Figure 1. Schematic diagram of target assembly and gauge placement. The right hand image shows the target assembly in section.

Slygard $184^{\mathrm{TM}}$ is supplied by Dow Corning ${ }^{\circledR}$ as a two part resin, with a base resin: hardener ratio of $c a$. 10:1. A curing agent (Dow Corning ${ }^{\circledR} 3-6559$ ) was added by 2.5 volume \%. After mixing, the resin was vacuum degassed for $c a .30$ minutes before casting into the target assembly shown in figure 1. Experimental conditions are summarized in table 1.

Table 1. Summary of Experimental Conditions.

\begin{tabular}{|l|l|l|l|}
\hline Flyer Material & Flyer Thickness (mm) & Impact Velocity $(\mathrm{m} / \mathrm{s})$ & Impact Stress (GPa) \\
\hline
\end{tabular}




\begin{tabular}{|l|l|l|l|}
\hline Dural & 6 & 280 & 0.52 \\
\hline Dural & 6 & 486 & 0.98 \\
\hline Copper & 6 & 498 & 1.21 \\
\hline Copper & 6 & 719 & 2.03 \\
\hline
\end{tabular}

The elastic properties were determined using quartz ultrasonic transducers at a frequency of $5 \mathrm{MHz}$.

\section{Materials}

The base resin polymer unit of Sylgard consists of a polymethylsiloxane (PDMS) molecule with either methyl or phenyl function groups (designated $R_{1}$ and $R_{2}$ ). The cure reaction occurs when the active silane hydrogen reacts with the vinyl group of an adjacent chain, in the presence of a platinum complex catalyst, forming a $\mathrm{CH}_{2}-\mathrm{CH}_{2}$ crosslink. A simplified representation of the polymer chains and the crosslinking reaction is presented in figure 2 .

The longitudinal $\left(c_{\mathrm{L}}\right)$ and shear $\left(c_{\mathrm{S}}\right)$ sound speeds were $1.10 \pm 0.02$ and $0.57 \pm 0.02 \mathrm{~mm}$ $\mu \mathrm{s}^{-1}$ respectively, yielding a Poisson's ratio of 0.316 . Density was measured at $1.01 \pm 0.01 \mathrm{~g}$ $\mathrm{m}^{-3}$.

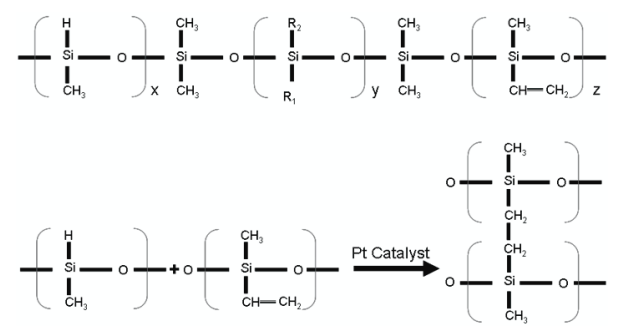

Figure 2. Simplified representation of the PDMS molecule and the crosslinking reaction.

Before moving onto the main subject of this paper, it is worth reviewing the existing Hugoniot data of Sylgard. We have taken data over the range of particle velocities of interest 
to this research from two sources; Marsh [25] and Winter et al. [26]. In figure 3, we show the relationship between shock velocity and particle velocity.

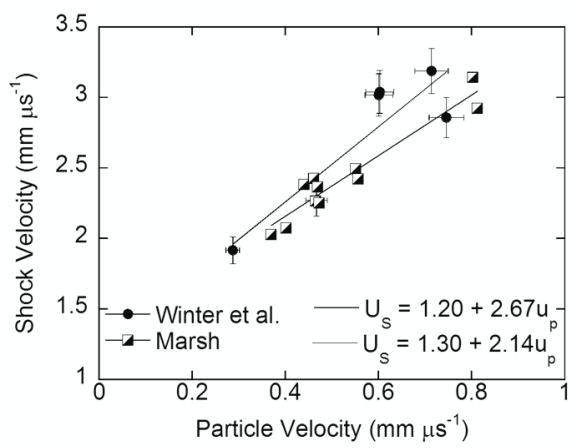

Figure 3. Shock velocity versus particle velocity for Sylgard $[25,26]$.

Both sets of data appear to follow a standard line relationship of the form,

$U_{S}=c_{0}+S u_{p}$,

where $c_{0}$ and $S$ are the shock parameters. Although there is an apparent difference between the two data sets, we believe that this is due to the degree of scatter present in both, and the fact that the particle velocity range is somewhat restricted. Therefore, we have followed the example of Winter et al. [26] and combined both sets of data to yielding values of $c_{0}$ and $S$ of $1.22 \mathrm{~mm} \mathrm{\mu s}^{-1}$ and 2.43 respectively. Observe that this value of $c_{0}$ (and indeed the separate values from figure 3 ) is higher than the ultrasonically measured value of $c_{\mathrm{L}}$. In metals, $c_{0}$ has been equated with the measured bulk sound speed $\left(c_{\mathrm{B}}\right)$, thus this discrepancy needs explanation. However, this behaviour has been observed in a number of other polymers, both by ourselves (see for example PEEK [17] and epoxy resins [16]) and in the compendium of polymer shock data published by Carter and Marsh [32]. In semicrystalline polmers [24], it was suggested that this be due to a deviation below the accepted linear response at very low particle velocities by a transition from elastic to inelastic behaviour in the stronger 
crystalline phase. However, this cannot happen in amorphous or glassy polymers such as Sylgard, and at present, the issue remains unclear.

In figure 4, we show the combined Hugoniot data in stress - particle velocity space for Sylgard, taken from Marsh [25] and Winter et al. [26].

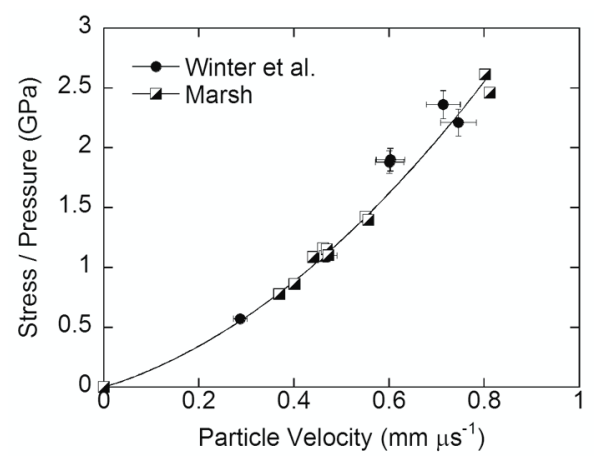

Figure 4. Hugoniot data for Sylgard.

The data has been curve fitted with a calculation of the hydrodynamic pressure $\left(P_{\mathrm{HD}}\right)$, according to,

$$
P_{H D}=\rho_{0} U_{S} u_{p},
$$

with $U_{\mathrm{S}}$ determined from equation 4 and the data presented in figure 3 . The values of $c_{0}$ and

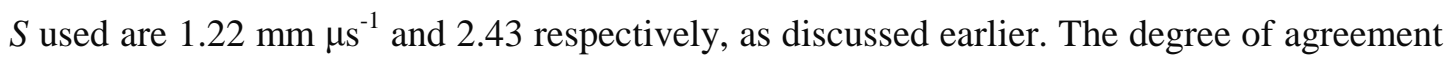
between measured stress [26] and calculated pressure and measured pressure [25] suggest, from equation 1 that the shock induced shear strength in Sylgard is low. We would point out that the hydrodynamic pressure discussed here is different from the hydrostatic pressure discussed earlier in equation 1 . Shock loading is an adiabatic process, hence considerable heat is generated. This will result in the material trying to increase in volume due to thermal expansion, which will be resisted by the inertial confinement present during one-dimensional strain (all strain is accommodated along the loading axis, hence the material undergoes a volume reduction behind the shock front compared to ambient conditions). As a 
consequence, this resistance to thermal expansion will lead to an increase in pressure, hence resulting in the hydrodynamic pressure being greater than its hydrostatic counterpart.

\section{Results.}

Representative lateral stress histories are presented in figure 5. Each trace is labeled with the longitudinal impact stress.

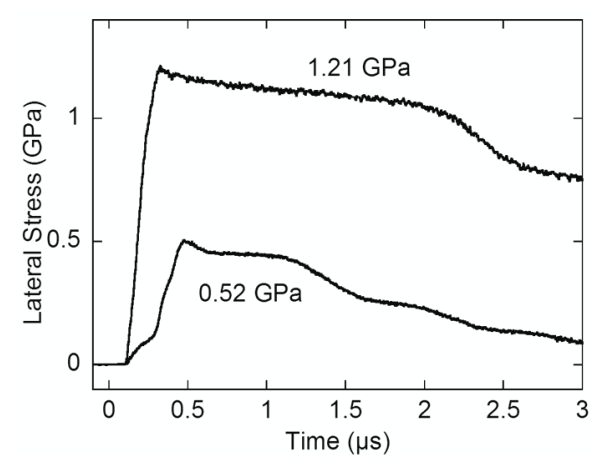

Figure 5. Representative lateral stress histories from Sylgard. Gauges are $4 \mathrm{~mm}$ from the

Sylgard / driver plate interface.

Both traces have features in common; a slight overshoot after arrival of the main shock, and a noticeable decrease in lateral stress behind the shock arrival, which from equation 2 indicates a corresponding increase in shear strength. The overshoot is an electrical effect due to the fast rising nature of the shock pulse, and is discussed in greater detail elsewhere. Also observe that on the trace labeled $0.52 \mathrm{GPa}$, there is a low amplitude step feature on the signal rise, of duration $c a .180 \mathrm{~ns}$. The first solution is that this is the result of the elastic response of the driver plate, in other words, the HEL of Dural. If true, this should correspond (approximately at least) with the wave separation of the elastic and plastic components of the shock in Dural over a distance of ca. $2 \mathrm{~mm}$. From the elastic wave speed $\left(6.40 \mathrm{~mm} \mu \mathrm{s}^{-1}\right)$ and the known shock response [10] $\left(U_{\mathrm{S}}=5.35+1.34 u_{\mathrm{p}}\right.$, giving $\left.U_{\mathrm{S}}=5.54 \mathrm{~mm} \mu \mathrm{s}^{-1}\right)$, this results in a 
temporal separation of $50 \mathrm{~ns}$, indicating that this solution is not correct. Therefore it would seem possible that this feature is a manifestation of the mechanical response of Sylgard.

The lateral stresses immediately behind the shock front have been used, along with the known longitudinal stresses to determine the shear strength of Sylgard. The results have been plotted against the corresponding longitudinal stress and the results are presented in figure 6 .

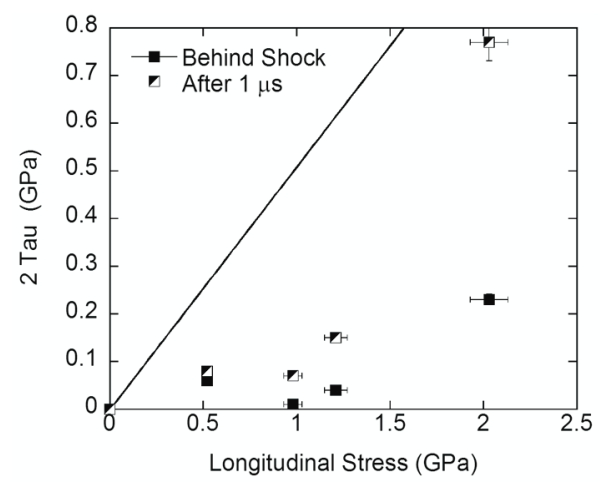

Figure 6. Shear strength versus impact stress for Sylgard.

The straight line is the calculated elastic response according to,

$$
2 \tau=\frac{1-2 v}{1-v} \sigma_{x} .
$$

As was suggested in the materials section, the resultant shear strength during shock loading is very low (the shear strength in for example epoxy resin [19] over a similar stress range lies between 0.25 and $0.60 \mathrm{GPa}$ ).

\section{Discussion.}

The main aim of this report is to investigate the shock induced shear strength in Sylgard. From figure 5, it is clear that the material undergoes a significant reduction in lateral stress behind the shock front. Assuming that $\sigma_{\mathrm{x}}$ is constant behind the shock front, then this implies, from equation 3 , that the shear strength is increasing until releases enter the gauge location. Such a response has been seen in a number of materials, including face-centred 
cubic metals, where it was explained in terms of dislocation multiplication [11], and more pertinently polymers such as PMMA [33], PEEK [17], polycarbonate [34], epoxy [16] and polyethylene, polypropylene and polystyrene [18]. Clearly dislocation based mechanisms cannot be operating, especially as these materials represent a range of semi-crystalline (PE, PP, PEEK), amorphous glassy (PMMA, polycarbonate, PS) and cross-linked thermosets (epoxy). It should be noted that all of these polymers contain open structures which would allow a high degree of tangling (steric interference) between adjacent chains. Note from figure 2 that the PDMS chain consists of alternating silicon and oxygen atoms, with the silicon atoms linked to either methyl or phenyl groups. This gives an open structure which will again lead to a high degree of steric interference. In addition, the cross linking between chains will also provide an extra source of resistance to compression. In this respect, Slygard is behaving in a similar way to the cross linked epoxy, although the strengths of this material are significantly higher since it is below its glass transition temperature, whilst Sylgard is above.

In most lateral gauge experiments it is necessary to section the specimen in half to introduce the gauge to the correct location, before re-assembling with an adhesive layer. Some reservations have been raised concerning this methodology [19], given that by its very nature, it is invasive. In a previous article, lateral stress gauge results in tungsten heavy alloy [20] have been shown to give the same results as those measured from pressure shear [35] or from differences between the Hugoniot and hydrostatic pressure [36]. Further, it has also been possible to relate changes in shear strength with both stress and pulse width to similar changes in shocked microstructure and spall strength [11], hence there is a high degree of confidence in the lateral gauge response. However, with Sylgard, it has been possible to cast the uncured material around the gauge itself without the need for sectioning. The fact that Slygard behaves in a similar manner to many other polymers is a further indication of the validity of the lateral stress gauge technique to determine the shock induced shear strength. 
The final feature requiring explanation is the small ramp noted on the lateral gauge trace labeled $0.52 \mathrm{GPa}$, shown in figure 5 . We reproduce it below in figure 7 , at a greater temporal resolution, below. We also include the rise times of two higher stress shots as well. Note that the ramp is also present at $0.98 \mathrm{GPa}$ (although of lower duration and higher amplitude) and is absent by $1.21 \mathrm{GPa}$. The solution most likely lies in a non-linear Hugoniot at low particle velocities. In the materials section it was noted that $c_{0}$, the zero particle velocity intercept of shock velocity lay significantly above the measured elastic wave speed, $c_{\mathrm{L}}$. It was suggested above that this may be due to a decrease in shock velocity below the linear response (see figure 3). In semi-crystalline polymers, it has been hypothesised that this behaviour may be due to elastic and inelastic deformation in the crystalline and amorphous phases respectively [24], but similar behaviour in amorphous polymers could not be explained in these terms.

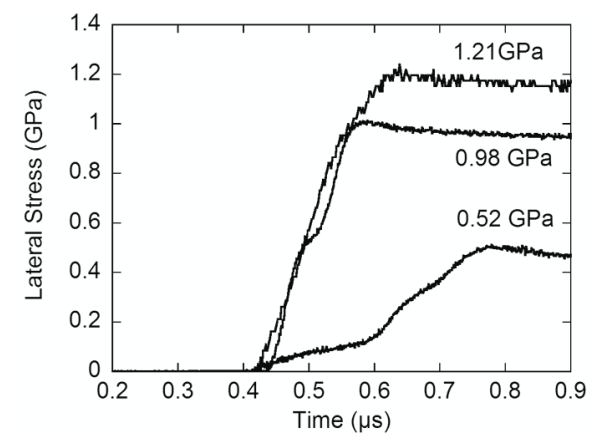

Figure 7. The behaviour of the rising part of the lateral stress pulse in Sylgard.

However, examination of the PDMS molecule in figure 2 shows the possibility of significant free volume under ambient conditions. During the early stages of shock compression, this free volume has the potential to collapse under pressure, thereby ramping the stress pulse before the material can reach a denser state and shock up. Dattelbaum and her colleagues [29] made similar observations concerning the non-linearity of $U_{\mathrm{S}}-u_{\mathrm{p}}$ data at low particle velocities, which would also agree with the Hugoniot data discussed in section 3, where the zero particle velocity intercept, $c_{0}$ is greater than the measured longitudinal sound speed. 


\section{Conclusions}

The response of the silicone based elastomer Sylgard $184^{\mathrm{TM}}$ to shock loading in terms of its lateral stress and shear strength. A re-examination of existing equation of state data, both from earlier work and from the literature gives an indication of a strong non-linearity at low particle velocities. A low amplitude ramp on the lower stress traces would appear to confirm this, and it has been hypothesised that the initially open structure of this cross-linked polymer would ramp the lower part of the shock. It has been noted that behind the shock front, lateral stress appears to decrease somewhat, suggesting a degree of hardening. This has been observed in a number of other polymers, and in common with those, it has been proposed that tangling between adjacent molecules (i.e. steric interference) is responsible. Finally, it has been observed that the overall trend is for the shear strength to increase with increasing impact stress, in common with many other materials.

\section{Acknowledgments.}

We would like to thank Pete Keightley, Mike Lowe, Nigel Park and Vince Durrant of AWE for their help and interest in this programme.

British Crown Copyright MoD/2010 


\section{References}

[1] M. U. Anderson, 1992 Shock Compression of Condensed Matter - 1991 ed S. C. Schmidt, R. D. Dick, J. W. Forbes and D. G. Tasker. (Amsterdam, Elsevier) pp875-8.

[2] M. A. Bohn, and P. Elsner, 1999 Propell. Explos. Pyrotech. 24 199-205.

[3] S.B. Haska, E. Bayramli, F. Perkel and S. Ozkar, 1997 J. Appl. Polym. Sci. 64 2347-54.

[4] D.P. Dandekar, C.A. Hall, L.C. Chhabildas and W.D. Reinhart, 2003 Composite Structures 61 51-9.

[5] E. Zaretsky, G. deBotton and M. Perl, 2004 Int. J. Solids Struct. 41 569-84.

[6] P. Buland, J. Dalbera and R. Lafolie 1995 10th European conference on Earthquake Engineering ed. Sum (Rotterdam, Balkema) pp. 2029-32.

[7] M. Zhou and R. J. Clifton, 1997 J. Appl. Mech. 64 487-94.

[8] D. P. Dandekar and W. J. Weisgerber 1999 Int. J. Plasticity 15 1291-1309.

[9] H. Huang and J. R. Asay 2007 J. Appl. Phys. 101063550.

[10] A. Hopkins and N. S. Brar 2000 Shock Compression of Condensed Matter 1999. eds M.

D. Furnish, L. C. Chhabildas and R. S. Hixson. (Melville, New York, American Institute of Physics) pp. 423-6.

[11] J.C.F. Millett, N.K. Bourne and G.T. Gray III, 2008 Met. Mat. Trans. A. 39 322-34.

[12] J.C.F. Millett, S.M. Stirk, N.K. Bourne, G.T. Gray III 2010 Acta Mater. 58 5675-82.

[13] N.S. Brar, S.J. Bless, Z. Rosenberg, 1991 Appl. Phys. Letts. 59 3396-8

[14] N. Bourne, J. Millett, Z. Rosenberg, N. Murray 1998 J. Mech. Phys. Solids. 46 18871908.

[15] N. Bourne, and J. Millett 2000 Proc. R. Soc. Lond. A 459 2673-88.

[16] J.C.F. Millett, N.K. Bourne, N.R. Barnes, 2002 J. Appl. Phys. 92 6590-4.

[17] J.C.F. Millett, N.K. Bourne, G.T. Gray III 2004 J. Phys. D: Applied Physics. 37 942-7.

[18] N. K. Bourne and J. C. F. Millett 2008 J. Mater. Sci. 43 185-9.

[19] R. E. Winter and E. J. Harris 2008 J. Phys. D. Applied Physics 41035503. 
[20] J.C.F. Millett, N.K. Bourne, Z. Rosenberg and J.E. Field, 1999 J. Appl. Phys. $866707-$ 9.

[21] J.C.F. Millett, N.K. Bourne and G.S. Stevens 2006 Int. J. Imp. Engng. 32 1086-94.

[22] P.J. Rae, E.N. Brown and E.B. Orler 2007 Polymer 48 568-615.

[23] N. K. Bourne, J. C. F. Millett, G.T. Gray III and P. Mort 2002 Shock Compression of Condensed Matter - 2001. ed. M. D. Furnish, N. Thadhani and Y. Horie (Melville, NY, American Institute of Physics) pp. 653-656.

[24] N.K. Bourne, J.C.F. Millett, E.N. Brown, G.T. Gray III 2007 J. Appl. Phys. 102063510.

[25] S. P. Marsh, 1980 LASL Shock Hugoniot data. Los Angeles, University of California Press.

[26] R.E. Winter, G. Whiteman, G. Haining, D.A. Salisbury and K. Tsembelis, 2004 Shock Compression of Condensed Matter - 2003 eds. M.D. Furnish, Y.M. Gupta and J.W. Forbes (Melville, NY, AIP Press) pp. 679-82.

[27] I. Be'ery and Z. Rosenberg 2008 Shock Compression of Condensed Matter - 2007 eds. M. Elert, M. D. Furnish, R. Chau, N. Holmes and J. Nguyen. (Melville, NY, AIP Press) pp. 1081-1084.

[28] R. Sander, N. Blais, R. Engelke, D. Dattelbaum, S. Sheffield, R. McInroy, 2006 Shock Compression of Condensed Matter - 2005 eds. M.D. Furnish, M. Elert, T.P. Russell and C.T. White (Melville, NY, AIP Press) pp. 1165-8.

[29] D.M. Dattelbaum, J.D. Jensen, A.M. Schwendt, E.M. Kober, M.W. Lewis and R. Menikoff, 2005 J. Chem. Phys. 122144903.

[30] J.B. Hooper, D. Bedrov, G.D. Smith, B. Hanson, O. Borodin, D.M. Dattelbaum and E.M. Kober 2009 J. Phys. Chem. 122144904

[31] Z. Rosenberg, N.K. Bourne, J.C.F. Millett, 2007 Meas. Sci. Technol. 18 1843-7

[32] W.J. Carter, S.P. Marsh, 1995 Hugoniot equation of state of polymers, Los Alamos National Laboratory Report No. LA-13006-MS (unpublished)

[33] J. C. F. Millett, and N. K. Bourne 2000 J. Appl. Phys. 88 7037-7040. 
[34] J. C. F. Millett, and N. K. Bourne 2006 J. Mater. Sci. 41 1683-1690.

[35] M. Zhou, and R. J. Clifton 1997 J. Appl. Mech. 64 487-494.

[36] D. P. Dandekar, and W. J. Weisgerber 1999 Int. J. Plasticity 15 1291-1309. 

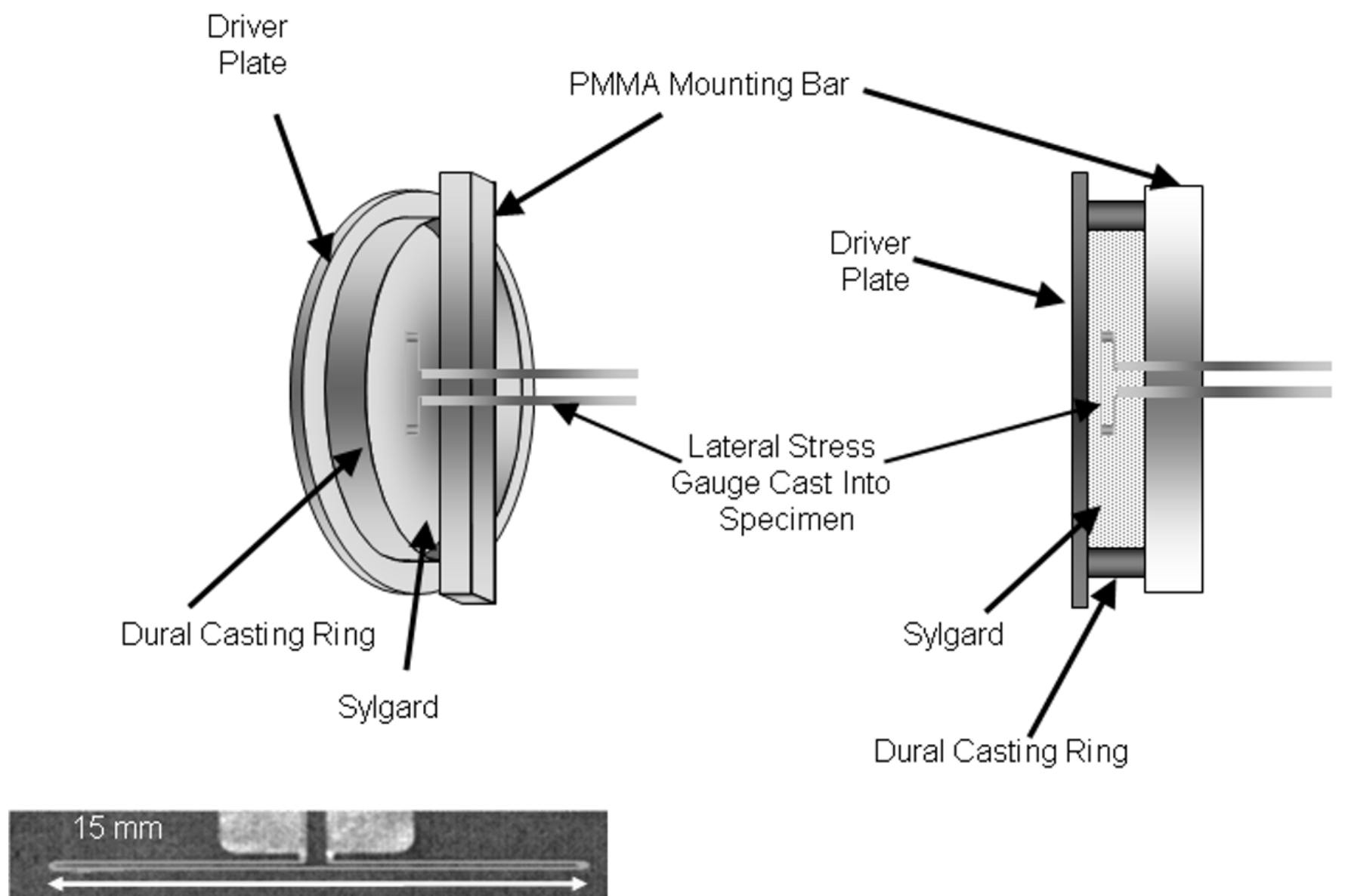

Active Width $=240 \mathrm{\mu m}$

Figure 1 (Figure1.tif) 


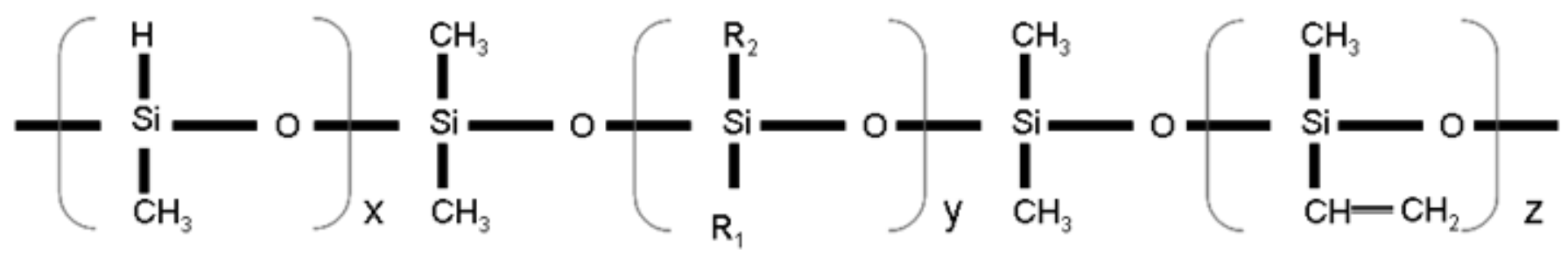

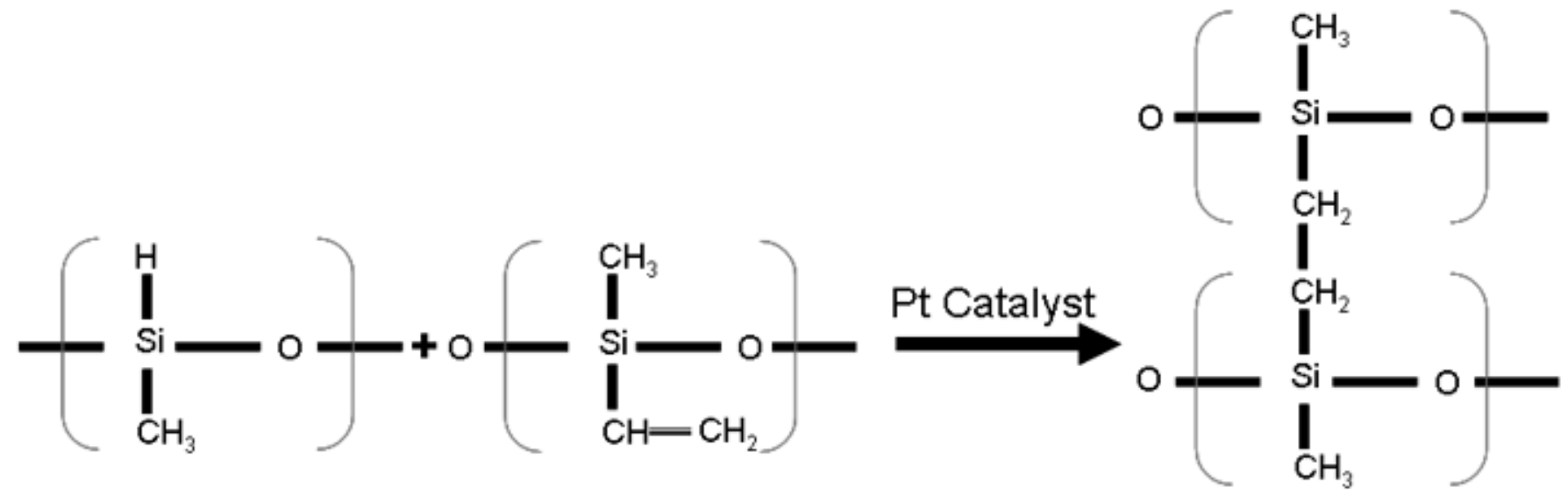

Figure 2 (Figure2.tif) 


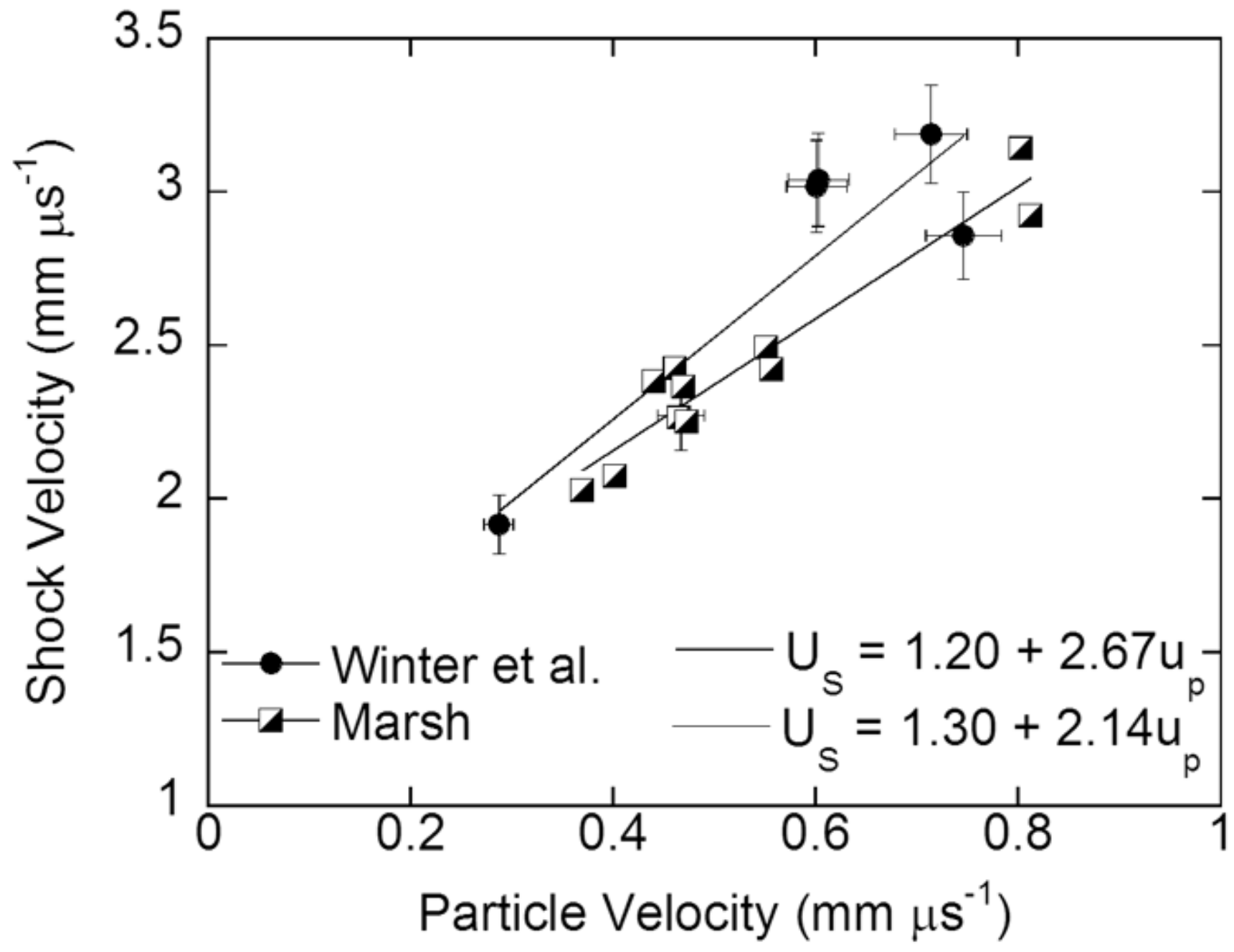

Figure 3 (Figure3.tif) 


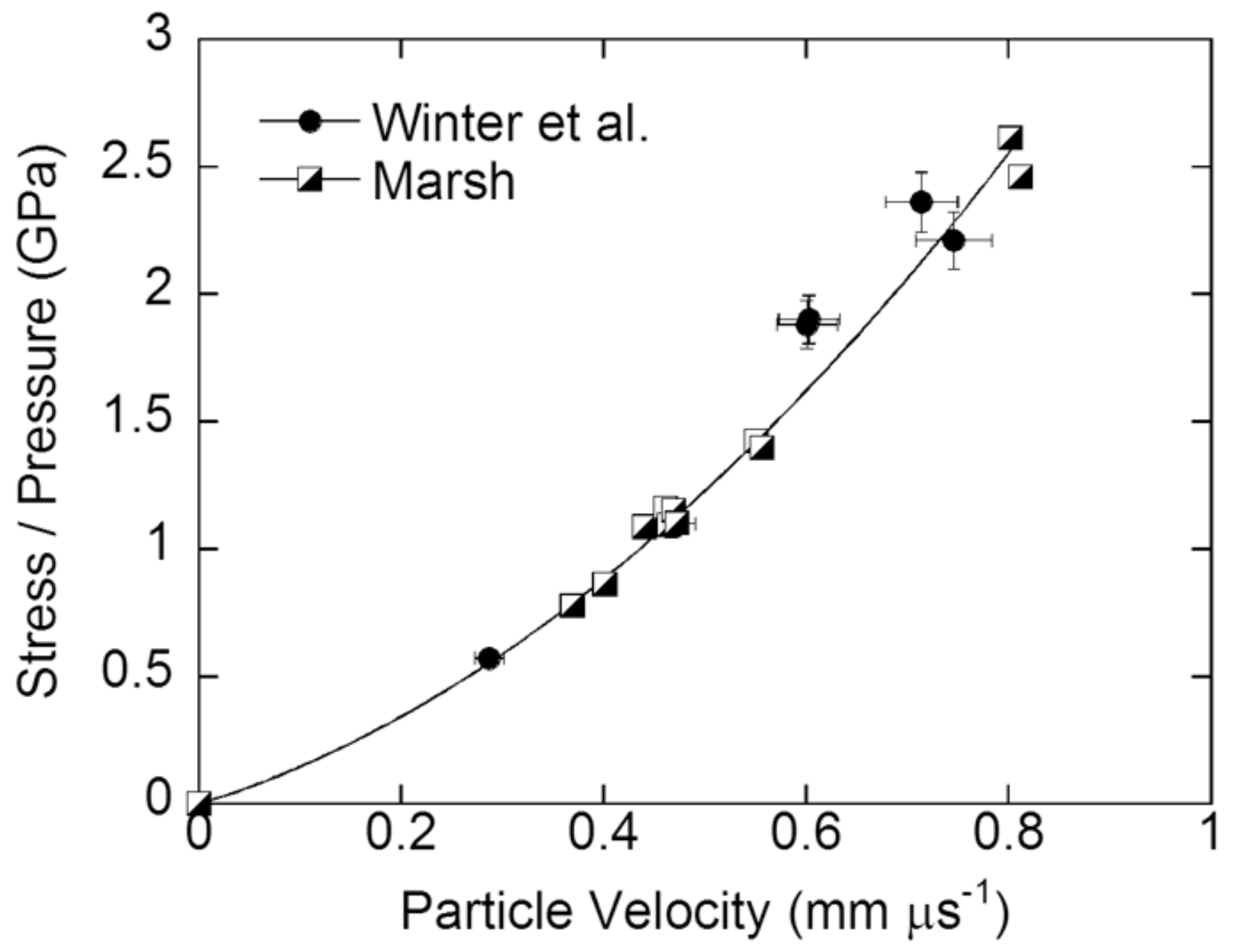

Figure 4 (Figure4.tif) 


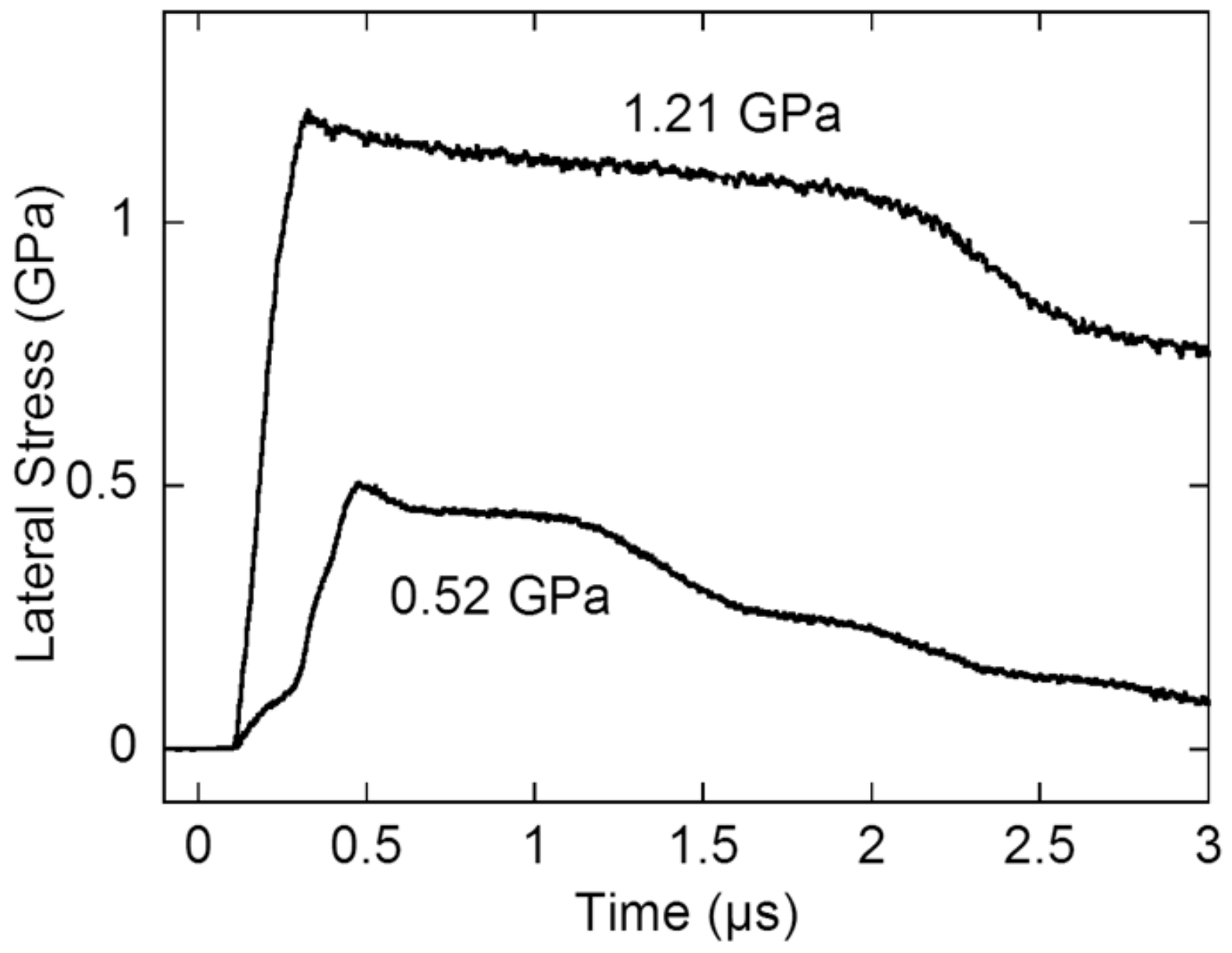

Figure 5 (Figure5.tif) 


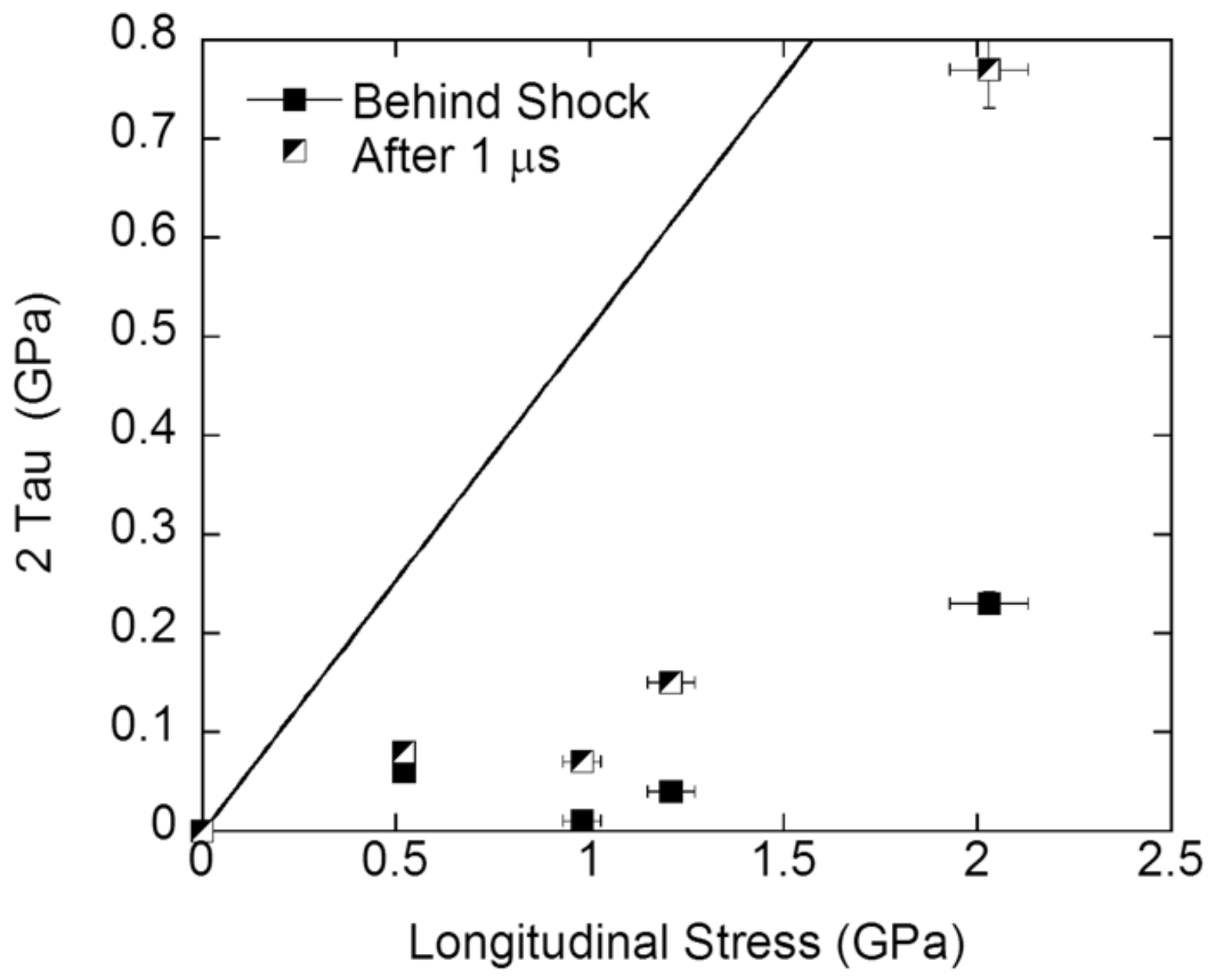

Figure 6 (Figure6.tif) 


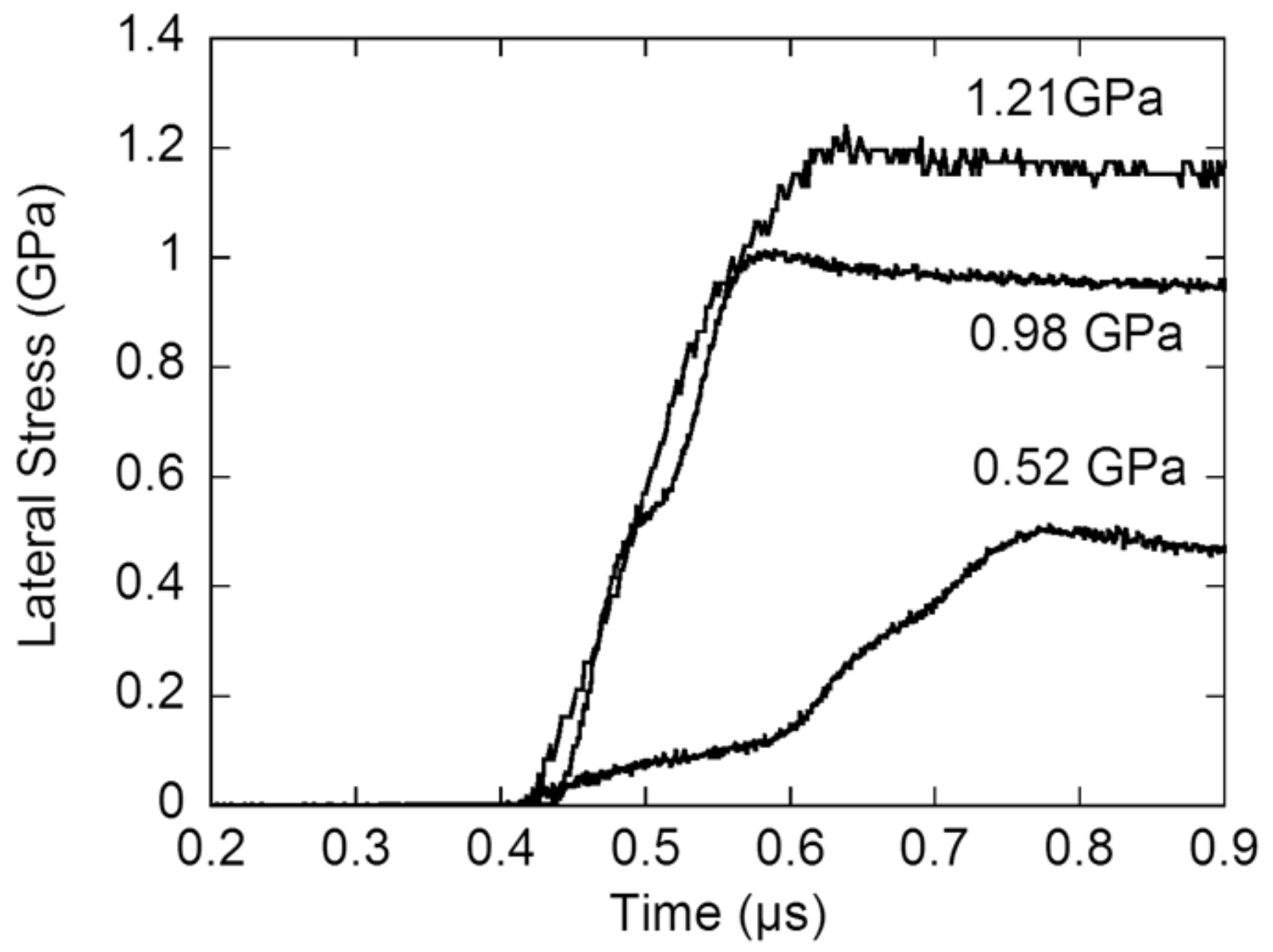

Figure 7 (Figure7.tif) 